\title{
Renal Protective Effect of Ginkgo biloba and L-carnitine Extracts against Pentylenetetrazol Induced Toxicity, Oxidative Stress, Injury and Proliferation Alternation in Epileptic Rats
}

\author{
Ehab Tousson $^{1^{*}}$, Akaber T. H. Keshta ${ }^{2}$, Youssef Hussein ${ }^{3,4}$, Reda M. Fekry ${ }^{2}$ \\ and Wafaa K. Abo-Ghaneima ${ }^{2}$ \\ ${ }^{1}$ Department of Zoology, Faculty of Science, Tanta University, Tanta, Egypt. \\ ${ }^{2}$ Department of Chemistry, Faculty of Science, Zagazig University, Egypt. \\ ${ }^{3}$ Department of Anatomy and Embryology, Faculty of Medicine, Mutah University, Jordan. \\ ${ }^{4}$ Department of Anatomy Faculty of Medicine, Zagazig University, Egypt.
}

\begin{abstract}
Authors' contributions
This work was carried out in collaboration among all authors. Author ET designed the study, performed the statistical analysis and wrote the protocol. Author WKAG wrote the first draft of the manuscript. Authors ATHK and YH managed the analyses of the study. Author YH managed the literature searches. All authors read and approved the final manuscript.
\end{abstract}

Article Information

DOI: $10.9734 / A R R B / 2019 /$ v32i230076

Editor(s):

(1) Dr. J. David Puett, Professor, Department of Biochemistry and Molecular Biology, University of Georgia, Athens, USA. (2) Prof. George Perry, Dean and Professor of Biology, University of Texas at San Antonio, USA, Adjunct Professor of Pathology and Neurosciences, Case Western Reserve University, Affiliate Professor of Chemistry and Biochemistry, University of Alaska, USA. Reviewers:

(1) Sandeep Kumar Agarwal, Christian Medical College, India.

(2) Dario Siniscalco, University of Campania, Italy. Complete Peer review History: http://www.sdiarticle3.com/review-history/49556

Original Research Article

Received 06 April 2019

Accepted 22 June 2019

Published 28 June 2019

\section{ABSTRACT}

Objectives: Ginkgo biloba leaf extract (GBLE) and L-carnitine extract are a commercial product used as a nutraceutic herbal widely. They have antioxidant and reactive oxygen species (ROS) scavenger. This study hypothesized that GB and L-carnitine may have protective effects against pentylenetetrazol (PTZ) induced oxidative damage in kidney in male albino rats.

Materials and Methods: A total of 80 male albino rats were equally divided into eight groups (G1, control; G2, GBLE; G3, L-carnitine; G4, Pentylenetetrazole; G5\&G6, pre and post treated PTZ with 
L-carnitine groups respectively; G7\&G8, pre and post treated PTZ with GBLE respectively). Results: Serum urea, creatinine, uric acid and cystatin $c$ were significantly increased in PTZ group when compared with control. Also; kidney homogenate MDA and DNA fragmentation were increased when compared with control while, significant decrease in CAT, SOD, GST and TAC in PTZ when compared with control. On other hand pre and post-treatment with L-carnitine and GBLE improved these parameters.

Conclusions: The results revealed that; the treatment with L-carnitine improved these parameters more than GBLE and the results of post treatment were better than pre-treatment.

Keywords: Pentylenetetrazole; Ginkgo biloba; L-carnitine; oxidative stress; DNA damage; kidney rats.

\section{INTRODUCTION}

Epilepsy is one of the most prevalent and serious neurologic conditions with high rates of disability and mortality [1]. Epileptic patients have liver and kidney damages both because of the epilepsy itself and antiepileptic drugs [2].

Pentylentetrazol (PTZ) kindling model provides a useful model for post seizure dysfunction, serving as a screen for potential treatments for the cognitive and emotional deficits that are observed in human epilepsy and caused inflammation of brain tissues [3]. Pentylenetetrazol induced morphological changes, cell death, apoptosis, neuronal activation in neuronal cells [4] and memory dysfunction [5].

Many plant extracts and their products have been shown to have significant antioxidant activities, which play important roles in alleviation and treatment of several ailments [6-10]. Ginkgo biloba is a popular supplement and one of the top-selling herbal medicines. Ginkgo biloba extract is collected from the dried green leaves of the plant and is available as liquid extracts, capsules, and tablets [1-11]. Ginkgo biloba (GB) leaf extract has widely consumed as herbal nutritional and used in the treatment and prevention of a variety of diseases as cognitive enhancers [12]. Gingko contains high levels of flavonoids and terpenoids, antioxidants that provide protection against oxidative cell damage from harmful free radicals [13-15].

L-carnitine is a naturally occurring amino acid derivative that's often taken as a supplement. In addition it plays a crucial role in the production of energy by transporting fatty acids into your cells' mitochondria [16-18], It has also as an antioxidant that reduces metabolic stress in the cells. L-carnitine may help increase mitochondrial function, which plays a key role in disease and healthy aging [19-21].
Therefore, the current study was carried out to evaluate the protective role of Ginkgo biloba and L-carnitine extracts against pentylenetetrazol induced renal toxicity, oxidative stress, and injury in epileptic rats.

\section{MATERIALS AND METHODS}

\subsection{Chemicals}

Pentylenetetrazol (PTZ): The reagents PTZ, thiobarbituric acid, 2,4dinitrophenylhydrazine, 5,5'-dithiobis(2-nitrobenzoic acid), (-)epinephrine, chlorogenic acid and guanidine hydrochloride were purchased from SigmaAldrich (St. Louis, MO, USA).

L-carnitine: The reagent L-carnitine ( $\beta$-hydroxy$\gamma$-trimethylaminobutyrate) was purchased from (Mepacomedifood medicine company) from (Anshase El-Ramle, Sharqia, Egypt).

Ginkgo biloba: The reagent Ginkgo biloba is dietary supplement for improving circulation and memory. It was purchased from (EMA Pharma pharmaceutical, Nozha, Nasr city, Cairo, Egypt).

\subsection{Animals Experiment}

The experimental protocol was approved by Local Ethics Committee and Animals Research. A total of 80 male Albino rats (Rattus norvigicus) (120 $\pm 10 \mathrm{~g}$ and of 7-8 weeks) were purchased from the breeding unit of the Egyptian Organization for Biological Products and Vaccines (Cairo, Egypt). The rats were kept in the laboratory for one week before the experimental work and maintained on standard diet and water was available ad libitum. Rearing and treatment of rats all over the experimental period were conducted in accordance with the Faculty of Science, Tanta University guide for animal, approved by Institutional Animal Care and Use Committee (IACUC-SCI-TU-0026). The rats were equally divided into eight groups. $1^{\text {st }}$ group was control group in which rats never 
received any treatment. $2^{\text {nd }}$ group was in which rats were treated with L-carnitine $(300 \mathrm{mg} / \mathrm{kg}$ body weight) once per day every other day for 9 days according to Tousson et al. [22]. $3^{\text {rd }}$ group was in which rats were treated with GBLE (100 $\mathrm{mg} / \mathrm{kg}$ body weight) once per day every other day for 9 days according to Tousson et al. [22]. $4^{\text {th }}$ group was in which rats were injected intraperitoneal (IP) with pentylenetetrazol (PTZ; $40 \mathrm{mg} / \mathrm{kg}$ body weight) once per day every other day for 9 days [22]. $5^{\text {th }}$ group; in which rats were pre-treated with L-carnitine for 9 days and then with pentylenetetrazol for another 9 days. $6^{\text {th }}$ group in which rats were injected IP with pentylenetetrazol for 9 days and then treated with L-carnitine for 9 days. $7^{\text {th }}$ group in which rats were pre-treated with GBLE for 9 days and then injected IP with pentylenetetrazol for another 9 days. 8th group in which rats were injected IP with pentylenetetrazol for 9 days and then treated with then treated with GBLE for 9 days.

\subsection{Estimation of Kidney Functions}

Serum urea, creatinine and uric acid were determined according to the method of Patton and Crouch [23] Bowers and Wong [24] while serum Cystatin $\mathrm{C}$ was determined according to the method of Tizon et al. [25].

\subsection{DNA Fragmentation}

The percentage of DNA fragmentation in kidney tissues was determined with diphenylamine spectrophotometric following the method described by Tousson et al. [26].

\subsection{Enzymatic and Non-enzymatic Antioxidant Assays}

Malondialdehyde (MDA) assay was detected in kidney tissuesby TBARS analysis and measured as reported by Tousson et al. [18]. Catalase (CAT) activity was detected according to the methods of Tousson et al. [27]. Superoxide dismutase (SOD) was detected according to the methods of El Atrash et al. [28]. Glutathione-Stranferase (GST) was determined according to the method of El-Demerdash et al. [29]. Total antioxidant capacity (TAC) activity was determined according to the method of Ibrahim et al. [30].

\subsection{Histological Examination}

Kidney was immediately removed from the dissected rats and divided into small pieces and immediately fixed by immersion in $10 \%$ buffered neutral formalin solution and left for 24-48 $\mathrm{h}$. The specimens were then dehydrated, cleared and embedded in paraffin. Serial sections of 5 $\mu \mathrm{m}$ thick were cut using mean of rotary microtome and stained with Haematoxylin and Eosin (H\&E) [26].

\subsection{Immunological Investigation}

Immune-labeling of PCNA antigen antibody was performed [31]. Briefly, the serial sections were dewaxed, hydrated, and immersed in an antigen retrieval solution $(0.01 \mathrm{M}$ citrate buffer, $\mathrm{pH} 6.0)$ for 15 minutes and autoclaved at $121^{\circ} \mathrm{C}$ for 15 minutes. They were then treated with hydrogen peroxide $0.3 \%$ and protein block, followed by incubation with anti-PCNA (clone PC10; 1: 200 Dako, Glostrup, Denmark) at $4^{\circ} \mathrm{C}$ overnight. The slides were rinsed three times with PBS, incubated with anti-mouse IgG secondary antibodies for 30 minutes at room temperature, visualized with diaminobenzidine commercial kits, and finally counterstained with Mayer's haematoxylin [26].

\subsection{Statistical Analysis}

Data were expressed as mean values $\pm S R$ and statistical analysis was performed using one way ANOVA to assess significant differences among groups of all treatments.

The criterion for statistical significance was set at $p<0.05$, at least, for the biochemical data. All statistical analyses were performed using SPSS statistical program, version 21 software package (SPSS $®$ Inc., USA).

\section{RESULTS}

\subsection{Kidney Functions}

Serum urea, creatinine, uric acids and cystatin $C$ levels in PTZ group were significantly increased when compared with control, L-carnitine and GBLE groups; On other hand, a significant decrease in the serum of urea, creatinine, uric acids and Cystatin C levels in PTZ+ L- carnitine and in L-carnitine + PTZ groups when compared with PTZ group. Also; there were significantly decreased in PTZ+GBLE group and GBLE+PTZ group when compared with PTZ group (Fig. 1a 1d).

\subsection{DNA Fragmentation}

DNA fragmentation levels in kidney in PTZ group were significantly increased when 
compared with control, L-carnitine and GBLE a groups; On other hand, a significant decreased changes in DNA fragmentation level in kidney in PTZ+ L- carnitine and L-carnitine + PTZ group when compared PTZ group. There was significantly decrease in PTZ + GBLE and GBLE+ PTZ group when compared with PTZ group (Fig. 2).

\subsection{Enzymatic and Non-enzymatic Antioxidant Assays}

SOD, CAT, GST and TAC levels in PTZ group showed significant decrease when compared with control, L-carnitine and GBLE groups. On the other hand, MDA levels in PTZ group showed significant increase when compared with control,
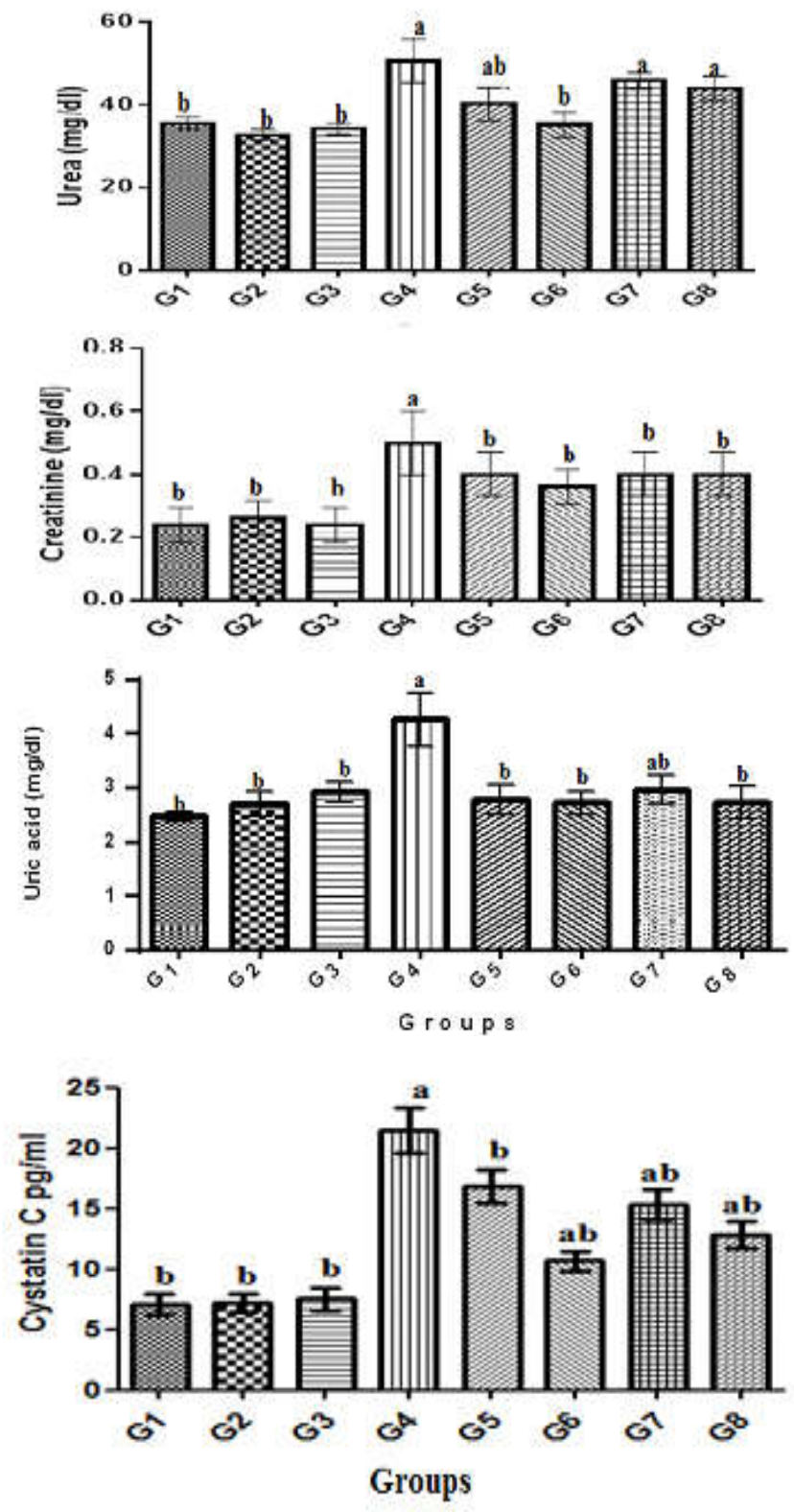

Fig. 1. Serum creatinine, urea, uric acids and Cystaitin $\mathrm{C}$ levels in different groups under study. $\left({ }^{\mathrm{a}}\right)$ Significant difference compared to control group. $\left({ }^{\mathrm{b}}\right)$ highly significant difference compared to PTZ group, where G1, control group; G2, L-carnitine group; G3, GBLE group; G4, PTZ group; G5\&G6, pre- and post- treated PTZ with L-carnitine groups respectively; G7\&G8, pre- and post- treated PTZ with Ginkgo biloba respectively 


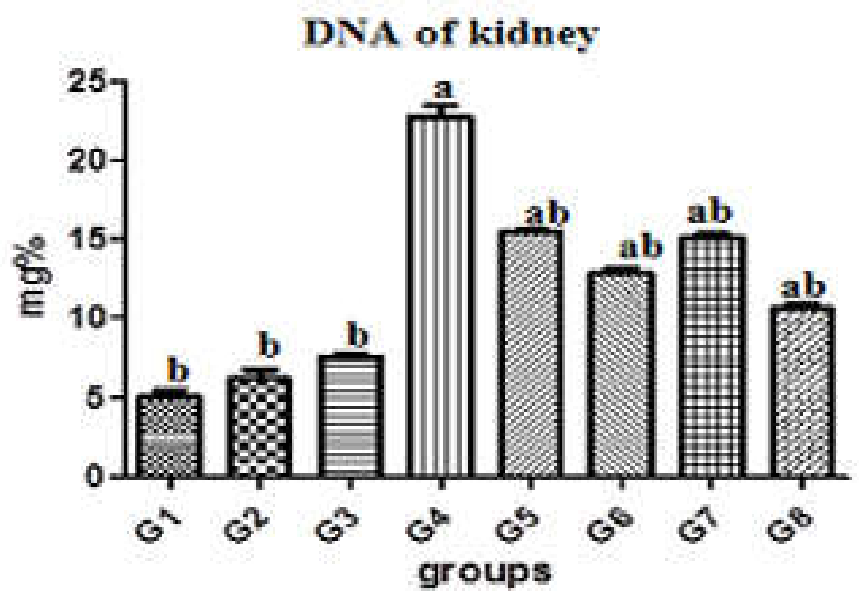

Fig. 2. Changes in kidney DNA fragmentation levels in different groups under study. $\left({ }^{a}\right)$ Significant difference compared to control group. $\left({ }^{b}\right)$ highly significant difference compared to PTZ group, where G1, control group; G2, L-carnitine group; G3,GBLE group; G4, PTZ group; G5\&G6, pre- and post- treated PTZ with L-carnitine groups respectively; G7\&G8, pre- and posttreated PTZ with GBLE respectively

L-carnitine and GBLE groups. In contrast, MDA levels in pre-treated PTZ group with L-carnitine or with GBLE groups (as in G5 \& G7) were significantly decreased when compared with PTZ group while catalase, SOD, GST and TAC levels in pre-treated PTZ group with L-carnitine or with GBLE groups (as in G5 \& G7) were significantly increased when compared with PTZ group. MDA levels in post treated PTZ group with L-carnitine with GBLE groups (as in G6 \& G8) were significantly decreased when compared with PTZ group while catalase, SOD, GST and TAC levels in post treated PTZ with L-carnitine with GBLE groups (as in G6\&G8) were significantly increased when compared with PTZ group (Table 1).

\subsection{Histological Examination}

The histological examination in kidney of control (G1), L-carnetine (G2) and GBLE (G3) groups showed normal structure of renal tubules and glomeruli. The renal corpuscle consisted of tuft of blood capillaries surrounded by the Bowmann's capsule. The renal tubules included proximal convoluted tubules lined by large pyramidal cells with a brush border and distal convoluted tubules lined by cuboidal cells (Fig. $3 A-3 C$ ). Kidney sections of PTZ (G4) group revealed remarkable changes in the renal cortex versus control animals. These changes were shrinkage of the glomeruli, tubular epithelial cells degeneration, tubular swelling, and some tubules are necrotic, multiple foci of haemorrhage, dilatation and congestion of blood vessels (Fig. 3D). Examination of kidney sections of rats pretreated groups with L-carnetine (G5) or GBLE (G7) revealed a mild degree of improvement in renal tubules and glomeruli where a moderate inflammatory infiltration and moderate vacuolated renal tubules (Fig. 3E \& 3G). On the other hand; Kidney sections of rats post-treated with Lcarnetine (G6) or GBLE (G8) revealed a good degree of improvement in renal tubules and glomeruli where the Kidney tissue restored most of its normal structure (Fig. $3 \mathrm{~F} \& 3 \mathrm{H}$ ).

\subsection{Immunological Investigation}

The detection and distribution of PCNA immunoreactivity (PCNA-ir) in kidney sections in the different groups were showed. Kidney sections in control (G1) group showed negative expression for PCNA-ir(grade 0) (Fig. 4A), while; faint positive to negative reactions for PCNA expressions (grade $1 \& 0$ respectively) in both renal tubules and glomeruli in kidney sections in L-carnetine (G2) and GBLE (G3) groups (Fig. 4B \& 4C). Moderate positive expression for PCNA-ir (grade 4) was detected in renal tubules and glomeruli in kidney sections in PTZ group (Fig. 7D). Moderate positive (grade 4) expression for PCNA-ir in kidney sections in pre-treated with L-carnetine and PTZ (G5) while 
mild positive expression (grade 2) for PCNA-ir in kidney sections in post-treated with L-carnetine and PTZ (G6) (Fig. 4E \& 4F). Kidney sections in pre-treated with ginkgo biloba and PTZ (G7) also in post-treated with ginkgo biloba and PTZ (G8) revealed mild to moderate reaction (grade 2 to 3 respectively) for PCNA-ir (Fig. 4G \& $4 \mathrm{H})$.
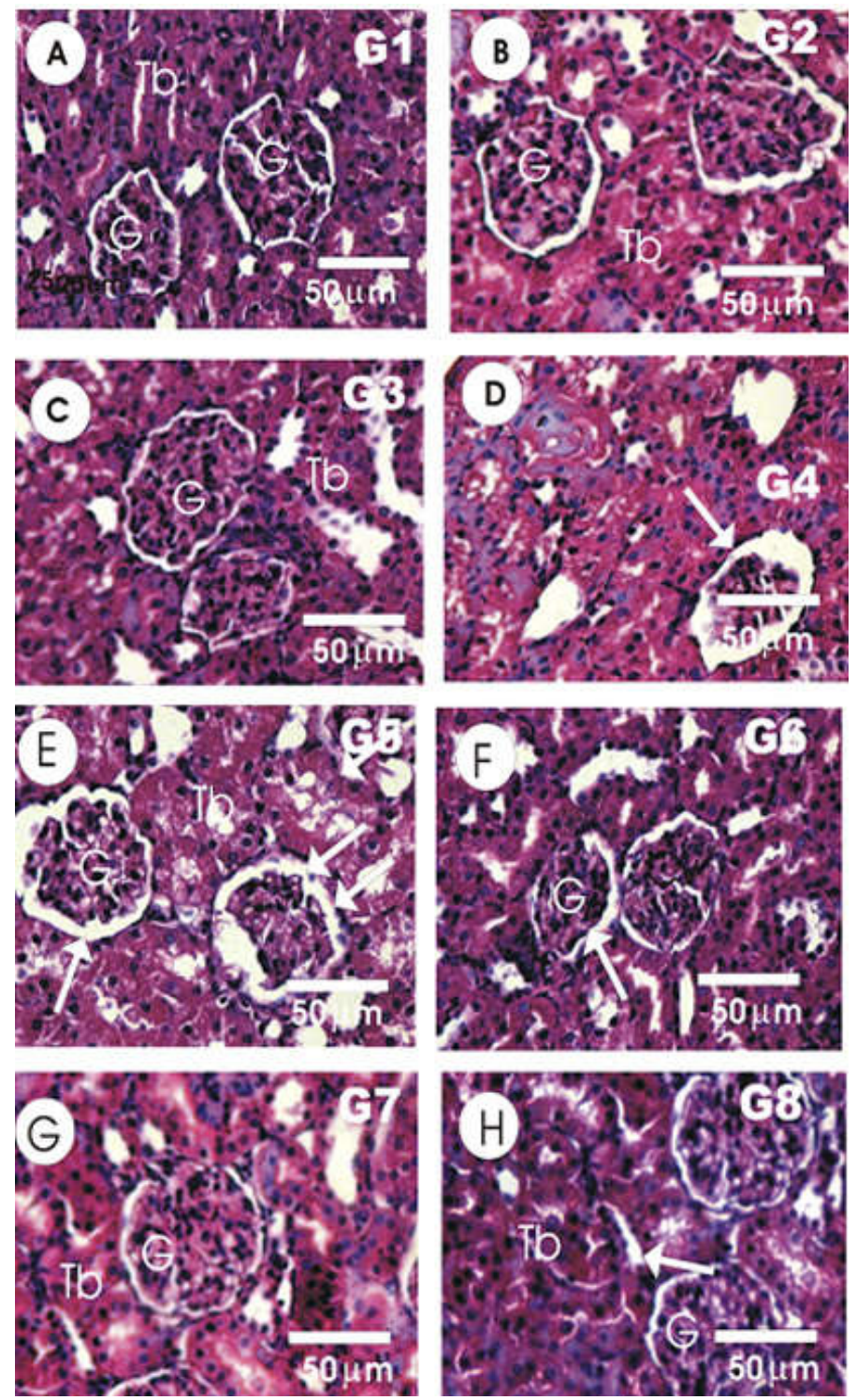

Fig. 3A-3H. Photomicrographs of rat kidney sections in the different groups stained with $\mathrm{H} \& \mathrm{E}$. A-C: kidney sections in control, L-carnitine and GBLE groups respectively showed normal structure of renal cortex with normal glomeruli, structure $(G)$ and renal tubules (Tb). D: kidney sections in PTZ group showed remarkable changes in the renal cortex versus control animals, these changes were shrinkage of the glomeruli, tubular epithelial cells degeneration, tubular swelling, some tubules are necrotic, multiple foci of haemorrhage, dilatation and congestion of blood vessels. E\&G: kidney sections in PTZ+L-carnitine and PTZ+ GBLE groups respectively showed revealed a mild degree of improvement in renal tubules and glomeruli where a moderate inflammatory infiltration and moderate vacuolated renal tubules. F\&H: kidney sections in L-carnitine+PTZ and GBLE+PTZ groups showed revealed a good degree of improvement in renal tubules and glomeruli where the Kidney tissue restored most of its normal structure 
Table 1. Changes in antioxidant and oxidative stress in different groups

\begin{tabular}{llllll}
\hline Groups & $\begin{array}{l}\text { MDA(n mole/gm } \\
\text { tissue) }\end{array}$ & CAT(U/g) & SOD(U/gm) & GST(U/g) & TAC(m Mole/L) \\
\hline G1 & $23.67 \pm 1.76^{\mathrm{b}}$ & $1.21 \pm 0.03^{\mathrm{b}}$ & $1168 \pm 15.3^{\mathrm{b}}$ & $2.30 \pm 0.15^{\mathrm{b}}$ & $0.88 \pm 0.06^{\mathrm{b}}$ \\
$\mathbf{G} 2$ & $25.33 \pm 1.9^{\mathrm{b}}$ & $1.45 \pm 0.02^{\mathrm{b}}$ & $1032 \pm 16.21^{\mathrm{b}}$ & $1.80 \pm 0.05^{\mathrm{b}}$ & $0.83 \pm 0.07^{\mathrm{b}}$ \\
$\mathbf{G 3}$ & $24.33 \pm 1.90^{\mathrm{b}}$ & $1.26 \pm 0.04^{\mathrm{b}}$ & $1008 \pm 11.92^{\mathrm{b}}$ & $1.48 \pm 0.10^{\mathrm{b}}$ & $0.73 \pm 0.06^{\mathrm{b}}$ \\
$\mathbf{G} 4$ & $58.50 \pm 3.45^{\mathrm{a}}$ & $0.50 \pm 0.08^{\mathrm{a}}$ & $356.7 \pm 8.4^{\mathrm{a}}$ & $0.68 \pm 0.07^{\mathrm{a}}$ & $0.30 \pm 0.05^{\mathrm{a}}$ \\
$\mathbf{G 5}$ & $39.00 \pm 2.42^{\mathrm{ab}}$ & $0.81 \pm 0.04^{\mathrm{ab}}$ & $549.2 \pm 11.43^{\mathrm{ab}}$ & $1.55 \pm 0.04^{\mathrm{b}}$ & $0.35 \pm 0.07^{\mathrm{a}}$ \\
$\mathbf{G 6}$ & $31.83 \pm 1.86^{\mathrm{ab}}$ & $1.40 \pm 0.03^{\mathrm{ab}}$ & $992.5 \pm 19.4^{\mathrm{b}}$ & $1.86 \pm 0.12^{\mathrm{b}}$ & $0.65 \pm 0.007^{\mathrm{b}}$ \\
$\mathbf{G 7}$ & $34.67 \pm 1.82^{\mathrm{ab}}$ & $0.93 \pm 0.04^{\mathrm{ab}}$ & $655.8 \pm 10.0^{\mathrm{ab}}$ & $1.25 \pm 0.09^{\mathrm{b}}$ & $0.41 \pm 0.007^{\mathrm{a}}$ \\
$\mathbf{G 8}$ & $36.67 \pm 1.97^{\mathrm{ab}}$ & $0.93 \pm 0.09^{\mathrm{ab}}$ & $852.5 \pm 15.26^{\mathrm{ab}}$ & $1.70 \pm 0.05^{\mathrm{b}}$ & $0.52 \pm 0.007^{\mathrm{ab}}$ \\
\hline
\end{tabular}

Data are expressed as mean \pm S.E.M of 10 observations. ( ${ }^{()}$) significant difference compared to control group. $\left.{ }^{b}\right)$ highly significant difference compared to PTZ group, where G1, control group; G2, L-carnitine group; G3, GBLE group; G4, PTZ group; G5\&G6, pre- and post- treated PTZ with L-carnitine groups respectively; G7\&G8, pre- and post- treated PTZ with GBLE respectively
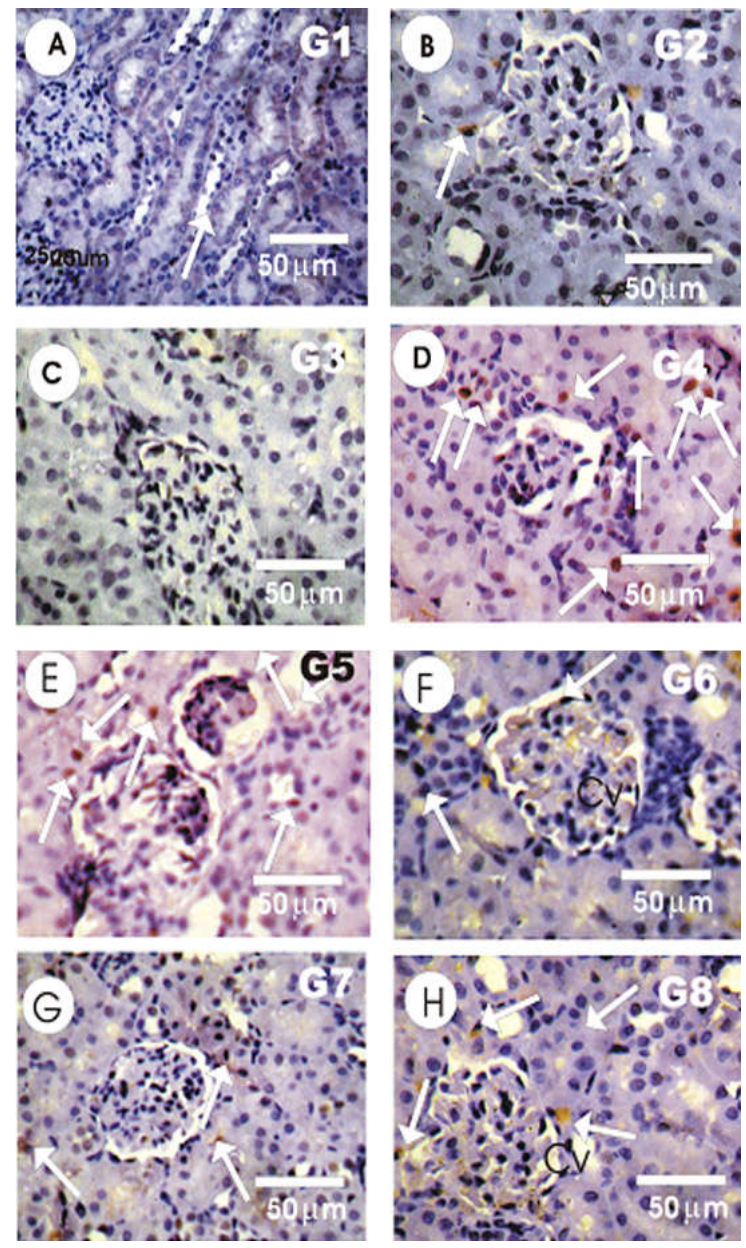

Fig. 4A-4H. PCNA-ir expressions in rat kidney sections in different groups under study. A\&B: Negative and mild expression in control and L-carnitie groups. C: Negative expression Ginkgo biloba group. D: Moderate expression in co-administrated PTZ group White arrows indicate moderate expression of PCNA renal tissues. E\&F: Moderate and mild expression in PTZ+Lcarnitie and L-carnitine + PTZ groups. G: Mild expression in PTZ+Ginkgo biloba group. H: Moderate expression in Ginkgo biloba +PTZ group White arrows indicate moderate expression of PCNA renal tissues 


\section{DISCUSSION}

Patient with epilepsy may suffer from renal or hepatic dysfunction that interferes with their antiepileptic drug treatment as well as their seizures. Recently there has been an increasing interest in the biochemical effects of medical plants with antioxidant properties, as they could be candidates for the prevention of oxidative damage [2]. This imbalance between the oxidant and antioxidant defenses may increase the risk of recurrent seizures [30].

This study conducts a biochemical investigation into whether L-carnitine and GBLE has a protective effect on pentylenetetrazole induced epilepsy in kidney male rats. The results of the studies indicate that pentylenetetrazole induced oxidative stress and tissue damage by increasing lipid peroxidation in the liver and kidney tissues and decreasing the level of antioxidant enzymes.

A significant rise in creatinine, urea and uric acids levels were observed after PTZ administration in serum when compared to control animals. On the other hand, a significant decrease in creatinine, urea and uric acids levels were observed in serum when treated with Lcarnitine. This decreased is possibly due to the modulatory activity of L-carnitine in the antioxidant enzymes in the kidney of adult rats. This indicates that L-carnitine inhibits kidney damage as free radical scavenger. Similarly, Tousson [20] reported that L-carnitine administration decrease the levels of creatinine, urea and uric acids in liver rats after induced with methotrexate. Treatment with pre and post GBLE significantly decreased creatinine, urea and uric acid level [20].

Oxidative stress can induce the accumulation of free radicals, destroy the antioxidant defense system, and inhibit the activities of antioxidant enzymes [27].

Lipid peroxidation, which is a normal phenomenon that occurs continuously at low levels in every individual, is the most common consequence of oxidative stress [31]. MDA is the last product of lipid peroxidation and is toxic to cells and cell membranes [32]. MDA elevate was reported to be present in newly diagnosed patients as an indicator of imbalance in the oxidative state $[33,34]$.

In the present study, a significant increase in MDA levels was observed after PTZ administration in homogenate of rat kidney when compared to control animals. The study agree with Dillioglugil et al. [35] reported that; an increase in MDA levels in liver and kidney after sound stimulate induced single and repeated convulsant seizure by PTZ. Also; Rodrigues et al. [36] reported that; an increase in MDA level in liver and serum after PTZ administration. Also; Koyuncuoglu et al. [5] reported that increase in MDA level in brain homogenate after PTZ administration in rats induced with an epileptic seizure. This reduction is possibly due to the modulator activity of L-carnitine in the antioxidant enzymes in the liver and kidney of adult rats. The present findings indicate that the effects of GBLE against oxidative damage may be due to its antioxidant and free radical-scavenging activity. The study agrees with Tousson et al. [22] who reported that L-carnitine administration has decreased levels of MDA in brain tissues in a rat seizure model.

Catalase serves as an antioxidant defense mechanism and is primarily responsible for the removal of $\mathrm{H}_{2} \mathrm{O}_{2}$ from cells form of oxygen and a normal cellular metabolite. Glutathione-STranseferase is one of the endogenous detoxifying antioxidant enzymes that lead to the formation of oxidized glutathione conjugates. Reduced GSH participates in the detoxification of xenobiotics as a substrate for the enzyme GST. Glutathione and other thiol containing proteins play a crucial key role in cellular defense against toxicity $[36,37]$.

In the present study; a significant decrease in SOD, catalase, GST and TAC levels were observed after PTZ administration. Also; previous study was reported, PTZ induced seizure shows marked reduction of antioxidant enzymes like glutathione reductase [38].

Köteles et al. [39] suggested that TAC levels were inversely correlated with cytogenetic radiation-induced damage in man, which means that antioxidant capacity is a protective factor against radiation hazard effects. These results are in accordance with Tousson et al. [22]; who showed marked reduction in antioxidant enzyme (SOD and catalase) in the PTZ-induced kindled group which leads to the production of free radicals and existence of oxidative stress in the brain. Also; Kumar and Rajkapoor [40] reported reduction in antioxidant level (SOD and catalase) after PTZ administration brain of rat. Also; Rauca et al. [41]; reported that PTZ-induced reduction in SOD activity in brain homogenate. 
The current results agree with Abdel-Wahab et al. [42] who reported that decrease in TAC level after PTZ administration in rat hippocampus. Our current results agree with Toklu et al. [43] who have reported decrease levels of TAC in urogenital organs in rat after administration of nicotine. Also; Goraca et al. [44] reported that; TAC associated with increased levels of lipid peroxidation and production of reactive oxygen species in liver and heart, depending on timing and distance from the field.

In the present study, rats treated with GBLE and $L$-carentine showed a significant decrease in the levels of MDA, and an increase in SOD, CAT, and GST activities in kidney as compared to control group. On the other hand, an improvement in the antioxidant status was observed in rats co-treated with both L-carentine and PTZ. Our results are in a good accordance with those obtained by Tousson et al. [22] who found that GBLE and L-carentine enhanced the antioxidant status and decreased the incidence of free radical-induced lipid peroxidation in the central nervous system of rats. Also; our current results agree with Tousson et al. [18] who studied the cardio-protective effects of L-carnitine on rat cardiac injury, apoptosis, and oxidative stress caused by amethopterin.

This results accepted to Bykov et al. [45] who have reported that L-carnitine administration have increased levels of TAC in liver and kidney tissues in a mouse seizure model El-Gindy et al. [46]; Zhang et al. [47] have reported increase levels of TAC as effects of GBLE of inhibition of total antioxidant activity. The present findings indicate that the effects of GBLE against oxidative damage may be due to its antioxidant and free radical-scavenging activity.

Cystatin $C$ is one of the major protectors of the intact glomerular basement membrane from damage by cysteine proteinases. It is isolated from urine in cases of tubular dysfunction while its serum level is increased in cases of impaired glomerular filtration rate [48]. Our present study showed that a significant increase in Cystatin $C$ levels was observed after PTZ administration in serum of rat when compared to control animals. The altered glomerular filtration rate also detected by the elevated serum Cystatin $C$ as it is an early marker of kidney affection than ordinary markers (e.g. creatinine) and can detect mild to moderate kidney affection. A significant reduction in Cystatin $C$ levels was observed in rat kidney when treated with L-carnitine. This reduction is possibly due to the modulator activity of L-carnitine in the antioxidant enzymes in the serum of adult rats. This indicates that $L$ carnitine inhibits kidney damage as free radical scavenger [48].

PTZ induced oxidative stress leading to the generation of free radicals which play an important role in lipid peroxidation, DNA damage and protein oxidation. Therefore, it could be suggested that the oxidative stress induced by PTZ may mediate the disturbance in cellular function and cell injury. A significant rise in DNA fragmentation levels in kidney homogenate was observed after PTZ administration when compared to control animals. This result is accepted by Dipti et al. [49] who reported increase in DNA fragmentation after lead induced oxidative stress. Also; Reyes et al. [50] has been shown that the increasing reactive products may give rise to deoxyribonucleic acid (DNA) injury during and as a result of lipid and protein oxidation in ureteral obstruction. Injury may also be greater with a decrease in antioxidant enzyme activities due to a reduction in antioxidant products and increased oxidant products in the cells in association with obstruction.

In the current study the kidney sections when PTZ administration showed remarkable changes in the renal cortex versus control animals. These changes were shrinkage of the glomeruli, tubular epithelial cells degeneration, tubular swelling, some tubules are necrotic, multiple foci of hemorrhage, dilatation and congestion of blood vessels Treatment with L-carnitine or GBLE revealed mild to moderate improvement in kidney sections. The histopathological results showed that, kidney of rats treated with GBLE showed moderate to good degree of improvement in Malpighian corpuscles in the kidney. So; PTZ led to oxidative stress in the rat kidney, while GBLE significantly prevented PTZ - induced oxidative stress. In the present study L-carnitine supplementation enhancement of renal damage induced by PTZ, and will be of major interest to be used as an adjuvant therapy under these conditions. L-carnitine is essential for the normal oxidation of fatty acids by the mitochondria and is involved in the transesterification and excretion of acyl-CoA esters, the oxidation of branched chain aketo acids, and removal of potentially toxic acylcarnitine esters from within mitochondria [51]. It is known that L-carnitine and its derivatives prevent the formation of ROS, scavenge free radicals and protect cells from pre-oxidative stress [52]. 
The intensity of PICNA-ir on kidney sections in PTZ administration detect moderate expression. pre-treated and post-treated with L-carnitine detect moderate and mild expression positive reaction of PCNA-ir. Kidney pre-treated with GBLE detect mild expression while,post-treated with GBLE detect moderate expression of PCNA renal tissues. So, it is therefore possible that Lcarnitine could scavenge free radicals and produce beneficial effects against PTZ kidney damage. Also; data so far obtained from this study would suggest that administration of GBLE after or before PTZ challenge may have beneficial effects that could possibly be ascribed, in part, to its regulation of the oxidant/anti-oxidant balance. So, it is therefore possible that GB could scavenge free radicals and produce beneficial effects against PTZ damage and PCNA alteration in kidney. The current study agrees with Peng et al. [53] who reported that Ginkgo has effectively suppressed the up regulated PCNA in Benign Prostate Hyperplasia. The present study agrees with Tousson et al. [20] who reported that PCNA expressions significantly decreased in liver and kidney sections after the treatments of Methotrexate with L-carnitine.

\section{CONCLUSIONS}

Pentylenetetrazole induced changes in kidney functions and structure, oxidative stress and DNA damage in male rats. The treatment with Icarnitine extract improved these changes more than Ginkgo biloba leaf extracts and the results of post treatment were better than pre-treatment.

\section{ETHICAL APPROVAL}

The experimental protocol was approved by Local Ethics Committee and Animals Research.

\section{COMPETING INTERESTS}

Authors have declared that no competing interests exist.

\section{REFFERENCES}

1. England MJ, Liverman CT, Schultz AM, Strawbridge LM. Epilepsy across the spectrum: Promoting health and understanding: A summary of the Institute of Medicine report. Epilepsy \& Behavior. 2012;25(2):266-76.

2. Birman H, Dar KA, Kapucu A, Acar S, Üzüm G. Effects of luteolinon liver, kidney and brain in pentylentetrazol- induced seizures: Involvement of metalloproteinases and NOS activities. Balkan Med J. 2012;29:188-196.

3. Barbalho PG, Cendes IL, Maurer-Morell CV. Indomethacin treatment prior to pentylenetetrazole-induced seizures downregulates the expression of $i l 1 b$ and cox2 and decreases seizure-like behavior in zebra fish larvae. BMC Neuro Science. 2016;7:17-12.

4. Sheng F, Chen M, Tan Y, Xiang C, Zhang M, Li B, Su H, He C, Wan J, Li P. Protective effects of otophylloside no pentylenetetrazol induced neuronal injury In vitro and In vivo. Front Pharmacol.; 2016.

DOI: 10.3389/fphar.2016.00224

5. Koyuncuoglu T, Vızdıklar C, Ürena D, Yılmaz H, Yıldırıma C, Atal SS, Akakınb D, Demirci EK, Yüksel $M$, Yegen BC. Obestatin improves oxidative brain damage and memory dysfunction in rats induced with an epileptic seizure. Peptides J. 2017;90:37-47.

6. Al-Rasheed NM, El-Masry TA, Tousson E, Hassan HM, Al-Ghadeer A. Protective potential of grape seed proanthocyandins extract against Glivec (ImatinibMesylate) induced liver toxicity and oxidative stress in male rats. Annual Research \& Review in Biology. 2017;20(6):1-9.

7. El-Masry TA, Al-Shaalan $\mathrm{NH}$, Tousson E, El-Morshedy K, Al-Ghadeer A. P53 expression in response to equigan induced testicular injury and oxidative stress in male rat and the possible prophylactic effect of star anise extracts. Annual Research \& Review in Biology. 2017;14(1): 1-8.

8. Oyouni AA, Saggu S, Tousson E, Mohan A, Farasani A. Mitochondrial nephrotoxicity induced by tacrolimus (FK-506) and modulatory effects of Bacopa monnieri (Farafakh) of Tabuk Region. Pharmacognosy Research. 2019;11(1):20.

9. Aldubayan MA, Elgharabawy RM, Ahmed AS, Tousson E. Antineoplastic activity and curative role of Avenanthramides against the growth of Ehrlich solid tumors in mice. Oxidative Medicine and Cellular Longevity. 2019;12. Article ID: 5162687. Available:https://doi.org/10.1155/2019/516 2687

10. AbdEldaim MA, Tousson E, El Sayed IE, Awd WM. Ameliorative effects of Saussurea lappa root aqueous extract against Ethephon-induced reproductive 
toxicity in male rats. Environmental Toxicology. 2019;34(2):150-9.

11. Tousson E, Atteya E, El-Atrash E, Jeweely OI. Abrogation by Ginkgo byloba leaf extract on hepatic and renal toxicity induced by methotrexate in rats. Journal of Cancer Research and Treatment. 2014; 2(3):44-51.

12. Teik DOL, Lee XS, Lim CJ, Low CM, Muslima M, Aquili L. Ginseng and Ginkgo biloba effects on cognition as modulated by cardiovascular reactivity: A randomised trial. PLoS ONE. 2016;11(3):1-20.

13. Guan $H$, Qian D, Ren H, Zhang W, Nie H, Shang $E$, Duan J. Interactions of pharmacokinetic profile of different parts from Ginkgo biloba extract in rats. J Ethnopharmacol. 2014;155(1):758-768.

14. Tousson E, Alghabban AJM, AbouHarga $\mathrm{H}$. Thyroidectomy induced hepatic toxicity and possible amelioration by Ginkgo biloba leaf extract. Biomedicine \& Preventive Nutrition. 2014;4(3):391-397.

15. González CEE, Andeola IGR, Juárez FJ, Ruvalcaba HM. Posadas del Rio FA. The Ginkgo biloba extract reverses the renal effects of titanium dioxide nanoparticles in adult male rats. Biochem Res Inter.; 2016. DOI: $10.1155 / 2016 / 5781579$

16. Salama AF, Kasem SM, Tousson E, Elsisy MK. Protective role of L-carnitine and vitamin $\mathrm{E}$ on the kidney of atherosclerotic rats. Biomedicine \& Aging Pathology. 2012;2:212-215.

17. Tousson E, Hegazy M, Hafez E, Ahmed EA. The effect of L-carnitine on Amethopterin-induced toxicity in rat large intestine. Journal of Cancer Research and Treatment. 2014;2(3):55-63.

18. Tousson E, Hafez E, Zaki S, Gad A. The cardioprotective effects of L-carnitine on rat cardiac injury, apoptosis, and oxidative stress caused by amethopterin. Environ Sci Pollut Res. 2016;23:20600-20608.

19. Salama A, Kasem S, Tousson E, Elsisy MK. Protective role of L-carnitine and vitamin $E$ on the testis of atherosclerotic rats. Toxicology and Industrial Health. 2015;31(5):467-474.

20. Tousson E, Tawfeek Z, Abu-Shaeir WA, Hassan $H$. Methotrexate-induced hepatic and renal toxicity: Role of L-carnitine in treatment. Biomedicine and Biotechnology. 2014;2(4):85-92.

21. Tousson E, Hafez E, Zaki S, Gad A. P53, $\mathrm{Bcl}-2$ and CD68 expression in response to amethopterin-induced lung injury and ameliorating role of I-carnitine. Biomedicine \& Pharmacotherapy. 2014;8(5):631-639.

22. Tousson E, Bayomy Mohamed FF, ElSendiony BF. Effects of L-carnitine and Ginkgo biloba on cerebral cortex in experimentally-induced epileptic seizures disease in rat. $\mathrm{J}$ Bioscience Applied. 2015;1(6):277-289.

23. Patton CJ, Crouch SR. Spectrophotometric and kinetics investigation of the Berthelot reaction for the determination of ammonia. Anal Chem. 1977;49:464-469.

24. Bowers LD, Wong ET. Kinetic serum creatinine assays. II. A critical evaluation and review. Lin. Chem. 1980;26(5):555561.

25. Tizon B, Ribe EM, Mi W, Troy CM, Levy EJ. Cystatin C protects neuronal cells from amyloid-beta-induced toxicity. Medine ALPDEMIR, Mehmet Fatihalpdemirturkish J Med Sci. 2010;19(3):885-894.

26. Tousson E. Histopathological alterations after a growth promoter boldenone injection in rabbits. Toxicology and Industrial Health. 2016;32(2):299-305.

27. Tousson E, Elgharabawy RM, Elmasry TA. Grape seed proanthocyanidin ameliorates cardiac toxicity induced by boldenoneundecylenate through inhibition of nadph oxidase and reduction in the expression of NOX2 and NOX4. Oxidative Medicine and Cellular Longevity. 2018;12. Article ID: 9434385.

Available:https://doi.org/10.1155/2018/943 4385

28. El Atrash A, Dawood L, Ehab Tousson, Salama A. Neuroprotective role of vitamin b3 in experimentally induced oxidative stress. International Journal of Clinical and Experimental Neurology. 2015;3(1):21-25.

29. El-Demerdash FM, Ehab M. Tousson, Kurzepa J, Habib SL. Xenobiotics, oxidative stress and antioxidants. Oxidative Medicine and Cellular Longevity. 2018;2. Article ID: 9758951.

Available:https://doi.org/10.1155/2018/975 8951

30. Ibrahim W, Tousson E, Ali EM, Mansour MA. Folic acid alleviates oxidative stress and hyperhomocysteinemia involved in testicular dysfunction of hypothyroid rats. General and Comparative Endocrinology. 2011;174:143-149.

31. Tousson E, El-Moghazy M, Massoud A, Akel A. Histopathological and immunohistochemical changes in the testes of rabbits after injection with the 
growth promoter boldenone. Reproductive Sciences. 2012;19(3):253-259.

32. Cengiz M, Yuksel A, Seven M. The effects of carbamazepine and valproic acid on the erythrocyte glutathione, glutathione peroxidase, superoxide dismutase and serum lipid peroxidation in epileptic children. Pharmacol Res. 2000;41(4):423425.

33. Saggu S, Sakeran M, Zidan N, Tousson E, Mohan A, Rehman H. Ameliorating effect of chicory (Chichorium intybus L.) fruit extract against 4-tert-octylphenol induced liver injury and oxidative stress in male rats. Food and Chemical Toxicology. 2014;72:138-146.

34. Rafat B, El Barbary A, Tousson E, Sami A. Meso-2,3-Dimercaptosuccinic acid (DMSA) and vitamin $C$ chelating potency in lead intoxication, regarding oxidative stress and apoptotic related protein in rabbit. $\mathrm{J}$. Genetic Engineering and Biotechnology. 2011;9(2):121-131.

35. Dillioglugil MO, Kir HM, Demir C, Ilbay G, Sahin D, Dillioglugil O, Bambal G, Mekik H, Ates N. Effect of pentylenetetrazole and sound stimulation induced single and repeated convulsive seizures on the MDA, GSH and NO levels, and SOD activities in rat liver and kidney tissues. Brain Res Bull. 2010;83:356-359.

36. Rodrigues AD, Scheffel TB, Scola G, Dos Santos MT, Fank B, Dani C, Vanderlinde $\mathrm{R}$, Henriques JAP, Coitinho AS, Salvador M. Purple grape juices prevent pentylenetetrazol induced oxidative damage in the liver and serum of Wistar rats. Nutrition Res. 2013;3:120-125.

37. Halliwell B, Gutteridge JMC. Free radicals in biology and medicine. Oxford: Oxford University Press; 1999.

38. Oyouni AA, Saggu S, Tousson E, Rehman H. Immunosuppressant drug tacrolimus induced mitochondrial nephrotoxicity, modified PCNA and Bcl-2 expression attenuated by Ocimum basilicum L. in CD1 mice. Toxicology Reports. 2018;5:687694.

39. Köteles GJ, Boitor I, Bognár G, Ótós M. Antioxidant status and cytogenetic injury. Centr Eur J Occup Environ Med. 2001;7: 217-227.

40. Kumar S, Rajkapoor B. Effect of Xanthium strumarium L. extracts on antioxidant enzymes levels in rat brain after induction of epilepsy. Pharmacology Online. 2010;2: 883-888.
41. Rauca C, Wiswedel I, Zerbe R, Keilhoff G, Krug M. The role of superoxide dismutase and alpha-tocopherol in the development of seizures and kindling induced by pentylenetetrazol - influence of the radical scavenger alpha-phenylN-tert-butyl nitrone. Brain Res. 2004;1009(1):203212.

42. Abdel-Wahab BA, Abd El-Aziz SM, AlQahtani JM. Effects of Omega-3 fatty acids on pentylenetetrazole-induced kindling, cognitive impairment and oxidative stress. J Life Sci. 2014;11(7):186-196.

43. Toklu H, Șehirli Ö, Şahin H, Çetinel Ș, Yeğen BC, Șener G. Resveratrol supplementation protects against chronic nicotine-induced oxidative damage and organ dysfunction in the rat urogenital system. Marmara Pharm J. 2010;14:2940.

44. Goraca A, Ciejka E, Piechota A. Effects of extremely low frequency magnetic field on the parameters of oxidative stress in heart. J Physiol Pharmacol. 2010;61:333-338.

45. Bykov IL, Maltsev AN, Gurinovich VA, Nefedov LI. Biochemical basis of valproic acid toxicity: Role of oxidative stress and effects of L-carnitine [in Russian]. Biomed Khim. 2004;50:384-389.

46. El-Gindy DMK, Mona FS, Runia F, El-Folly AR, Abdel-Kader. The clinical outcome of the extract of Ginkgo biloba in Egyptian chronic hepatitis C patients. J Drug Res. 2014;35(1):11-21.

47. Zhang CA, Zhu Y, Wang J, Xu H, Ren W. Ginkgo biloba extract EGb 761 alleviates hepatic. Fibrosis and sinusoidal microcirculation disturbance in patients with chronic hepatitis B. Gastroenterol Res. 2008;26(10):1283-1290.

48. Parikh CR, Devarajan P. New biomarkers of acute kidney injury. Crit Care Med. 2008;36(4):159-165.

49. Dipti P, Yogesh B, Kain AK, Pauline T, Anju B, Sairam M, Singh B, Mongia SS, Kumar IGD, Selvamurthy W. Lead induced oxidative stress: Beneficial effects of Kombucha tea. Biomed Environm Sci. 2003;16:276-282.

50. Reyes JL, Molina-Jijón E, RodríguezMuñoz R, Bautista-García P, DebrayGarcía Y, NamoradoMaría DC. Tight junction proteins and oxidative stress in heavy metals induced nephrotoxicity. Biomed Res Int. 2013;2(13):730-789.

51. Rebouche CJ, Seim H. Carnitine metabolism and its regulation in 
microorganisms and mammals. Annu Rev Nutr. 1998;18:39-61.

52. Sener G, Eksioglu-demiralp E, Cetiner M, Ercan F, Sirvanci S, Gedik N. L-Carnitine ameliorates methotrexate-induced oxidative organ injury and inhibits leukocyte death. Cell Biol Toxicol. 2006;22:47-60.
53. Peng CC, Liu JH, Chang $\mathrm{CH}$, Chung JY, Chen KC, Chou KY, Peng RY. Action mechanism of Ginkgo biloba leaf extract intervened by exercise therapy in treatment of benign prostate hyperplasia. Evidence-Based Complementary Alternative Med. 2013;1:1-12.

(c) 2019 Tousson et al.; This is an Open Access article distributed under the terms of the Creative Commons Attribution License (http://creativecommons.org/licenses/by/4.0), which permits unrestricted use, distribution, and reproduction in any medium, provided the original work is properly cited.

Peer-review history:

The peer review history for this paper can be accessed here: http://www.sdiarticle3.com/review-history/49556 